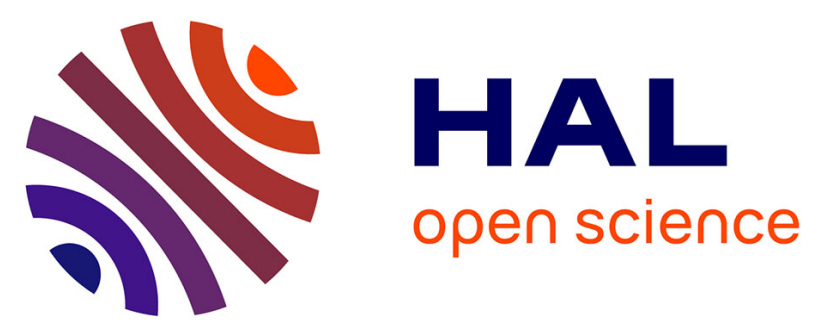

\title{
Modulating the pro-apoptotic activity of cytochrome c at a biomimetic electrified interface
}

\author{
Alonso Gamero-Quijano, Shayon Bhattacharya, Pierre-André Cazade, Andrés \\ F Molina-Osorio, Cillian Beecher, Ahmed Djeghader, Tewfik Soulimane, \\ Manuel Dossot, Damien Thompson, Grégoire Herzog, et al.
}

\section{To cite this version:}

Alonso Gamero-Quijano, Shayon Bhattacharya, Pierre-André Cazade, Andrés F Molina-Osorio, Cillian Beecher, et al.. Modulating the pro-apoptotic activity of cytochrome c at a biomimetic electrified interface. Science Advances , 2021, 7 (45), 10.1126/sciadv.abg4119 . hal-03423494

\section{HAL Id: hal-03423494 \\ https://hal.univ-lorraine.fr/hal-03423494}

Submitted on 10 Nov 2021

HAL is a multi-disciplinary open access archive for the deposit and dissemination of scientific research documents, whether they are published or not. The documents may come from teaching and research institutions in France or abroad, or from public or private research centers.
L'archive ouverte pluridisciplinaire HAL, est destinée au dépôt et à la diffusion de documents scientifiques de niveau recherche, publiés ou non, émanant des établissements d'enseignement et de recherche français ou étrangers, des laboratoires publics ou privés.

\section{(ㄷ)(1) $\$$}

Distributed under a Creative Commons Attribution - NonCommerciall 4.0 International 


\section{Modulating the pro-apoptotic activity of cytochrome c at a biomimetic electrified interface}

\author{
Alonso Gamero-Quijano ${ }^{1,2}$, Shayon Bhattacharya ${ }^{1,3}$, Pierre-André Cazade ${ }^{1,3}$, \\ Andrés F. Molina-Osorio ${ }^{1,2}$, Cillian Beecher ${ }^{1,2}$, Ahmed Djeghader ${ }^{2}$, Tewfik Soulimane ${ }^{2}$, \\ Manuel Dossot ${ }^{4}$, Damien Thompson ${ }^{1,3 *}$, Grégoire Herzog ${ }^{4 *}$, Micheál D. Scanlon ${ }^{1,2,5 *}$
}

\begin{abstract}
Programmed cell death via apoptosis is a natural defence against excessive cell division, crucial for fetal development to maintenance of homeostasis and elimination of precancerous and senescent cells. Here, we demonstrate an electrified liquid biointerface that replicates the molecular machinery of the inner mitochondrial membrane at the onset of apoptosis. By mimicking in vivo cytochrome c (Cyt c) interactions with cell membranes, our platform allows us to modulate the conformational plasticity of the protein by simply varying the electrochemical environment at an aqueous-organic interface. We observe interfacial electron transfer between an organic electron donor decamethylferrocene and $\mathrm{O}_{2}$, electrocatalyzed by $\mathrm{Cyt}$ c. This interfacial reaction requires partial Cyt c unfolding, mimicking Cyt $c$ in vivo peroxidase activity. As proof of concept, we use our electrified liquid biointerface to identify drug molecules, such as bifonazole, that can potentially down-regulate Cyt $\mathrm{c}$ and protect against uncontrolled neuronal cell death in neurodegenerative disorders.
\end{abstract}

\section{INTRODUCTION}

Cytochrome c (Cyt c) conformational plasticity enables its biological functional versatility (1). During homeostasis, the Cyt c protein plays an essential role in the mitochondrial electron transfer chain, shuttling electrons from Cyt $\mathrm{c}$ reductase (the $b c 1$ complex) to Cyt $\mathrm{c}$ oxidase (2). Under cell stress, the mitochondrial membrane rearranges, making cardiolipin (CL) phospholipids available to bind Cyt c (3). Positively charged Cyt c stabilizes the anionic CL headgroup, and CL tucks its hydrophobic tail inside Cyt c, loosening the tertiary structure and enhancing catalytic peroxidase activity by increasing the accessibility of small molecules (such as $\mathrm{H}_{2} \mathrm{O}_{2}$ ) to the heme pocket $(4,5)$. Oxidation of CL releases Cyt $\mathrm{c}$ from the inner mitochondrial membrane and its passage into the cytosol marks the "point of no return" for programmed cell death (6-8). Thus, drugs designed to block the heme prosthetic group of Cyt c may counteract excessive apoptosis $(9,10)$ and lead to therapies that alleviate neurodegenerative diseases (11-14) and reduce loss of healthy cells during radiotherapy (15).

In this work, we mimic the in vivo Cyt c-lipid membrane interactions by externally controlling the electrostatic potential at an immiscible aqueous-organic interface. Positively biasing this liquid biointerface induces the adsorption of cationic Cyt c from the aqueous phase and enriches the organic side with tetrakis(pentafluorophenyl)borate electrolyte hydrophobic anions $\left(\mathrm{TB}^{-}\right)(16)$. Acting as a CL-like "soft matter disruptor" $(17,18), \mathrm{TB}^{-}$interacts with interfacial Cyt c, opening up the heme pocket. Atomistic molecular dynamics (MD) computer simulations confirm that positively biasing the interface promotes electrostatic attraction between $\mathrm{TB}^{-}$and Cyt $\mathrm{c}$

\footnotetext{
${ }^{1}$ The Bernal Institute, University of Limerick (UL), Limerick V94 T9PX, Ireland. ${ }^{2}$ Department of Chemical Sciences, School of Natural Sciences, University of Limerick (UL), Limerick V94 T9PX, Ireland. ${ }^{3}$ Department of Physics, School of Natural Sciences, University of Limerick (UL), Limerick V94 T9PX, Ireland. ${ }^{4}$ Laboratoire de Chimie Physique et Microbiologie pour les Matériaux et l'Environnement, Université de Lorraine, CNRS, LCPME, F-54000 Nancy, France. ${ }^{5}$ Advanced Materials and Bioengineering Research (AMBER) Centre, Dublin, Ireland.

*Corresponding author. Email: damien.thompson@ul.ie (D.T.); gregoire.herzog@ univ-lorraine.fr (G.H.); micheal.scanlon@ul.ie (M.D.S.)
}

positively charged lysine $\varepsilon$-amino sidechains. These interactions project the heme pocket toward the organic phase, creating a junction for interfacial electron transfer (IET). Addition of reductant decamethylferrocene (DcMFc) to the organic phase makes Cyt c a potent $\mathrm{O}_{2}$ reduction electrocatalyst. This potential-induced flow of electrons mimics in vivo Cyt $\mathrm{c}$ peroxidase activity in which reactive $\mathrm{O}_{2}$ species (ROS; such as $\mathrm{H}_{2} \mathrm{O}_{2}$ ) are reduced at the heme. Thus, the dual biological role of $\mathrm{CL}$ as a disrupter of the tertiary structure of Cyt $\mathrm{c}$ and sacrificial oxidant is played by $\mathrm{TB}^{-}$and $\mathrm{DcMFc}$, respectively, at the biomimetic aqueous-organic interface (Fig. 1). The current produced during interfacial $\mathrm{O}_{2}$ reduction by Cyt c provides a distinct, robust electrochemical signature to monitor activation and drug-induced deactivation of the heme active site.

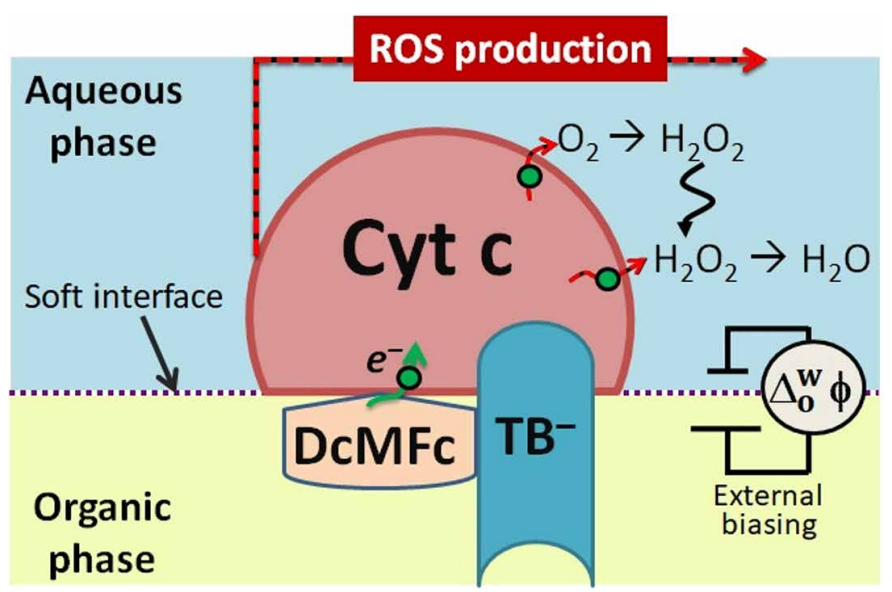

Fig. 1. Biomimetic electrified aqueous-organic interface at which DcMFc and tetrakis(pentafluorophenyl)borate anions ( $\mathrm{TB}^{-}$) activate $\mathrm{Cyt} \mathbf{c}$ for reduction of ROS. The aqueous phase is a phosphate buffer at $\mathrm{pH} 7$ and the organic phase is $\alpha, \alpha, \alpha$-trifluorotoluene (TFT). The electrons are represented by green circles, and the interfacial Galvani potential difference $\left(\Delta_{\mathrm{o}}^{\mathrm{w}} \phi\right)$ can be modulated externally by a potentiostat. 


\section{RESULTS}

\section{Mimicking in vivo Cyt c-lipid interactions}

Precise control of the strength of Cyt $\mathrm{c}$ adsorption at the aqueousorganic interface between water and $\alpha, \alpha, \alpha$-trifluorotoluene (TFT) is the crucial first step to mimic in vivo Cyt c-lipid interactions. Weakly or nonadsorbing Cyt $\mathrm{c}$ remains in its native fully folded, noncatalytic state, while very strong adsorption causes full denaturation, leading to aggregation and deactivation (19). As shown below, at our liquid biointerface, the extent of adsorption is tailored electrochemically to achieve the required thin film of partially denatured Cyt c with the essential access of the heme catalytic site to small molecules. The water-TFT interface may be biased (or charged) externally using a power source or by partition of a common ion between the phases (20-22). At positive bias, the interface is charged by a buildup of aqueous cations and organic anions (and vice versa for negative bias), forming back-to-back ionic distributions. Thus, at positive bias, coulombic interactions between cationic aqueous Cyt c (net charge of approximately +9 in its oxidized form at $\mathrm{pH} 7$ ) (23) and the organic electrolyte $\mathrm{TB}^{-}$anions are favored at the interface.

The interfacial adsorption of Cyt $\mathrm{c}$ was monitored spectroscopically by ultraviolet-visible total internal reflection spectroscopy (UV/vis-TIR). In open-circuit potential (OCP) conditions (Fig. 2A, top) or with a negative bias set by the partition of tetrabutylammonium cations (Fig. 2A, bottom), the UV/vis-TIR spectra were featureless, indicating that Cyt $\mathrm{c}$ does not adsorb spontaneously at the water-TFT interface nor when its approach to the interface is electrochemically inhibited. However, with a positive bias, set by partition of $\mathrm{Li}^{+}$, a clear absorbance signal appears, with the heme Soret band growing in magnitude over time (Fig. 2B). The Soret peak position $\left(\lambda_{\max }=405 \mathrm{~nm}\right)$ was blue-shifted compared to the native oxidized form of Cyt $\mathrm{c}\left(\lambda_{\max }=408 \mathrm{~nm}\right)$, indicating disruption of the heme iron sphere coordination (24). This time-dependent increase in magnitude of the Soret band indicated multilayer adsorption of Cyt $\mathrm{c}$ at positive bias. The conformational shift in Cyt $\mathrm{c}$ at positive

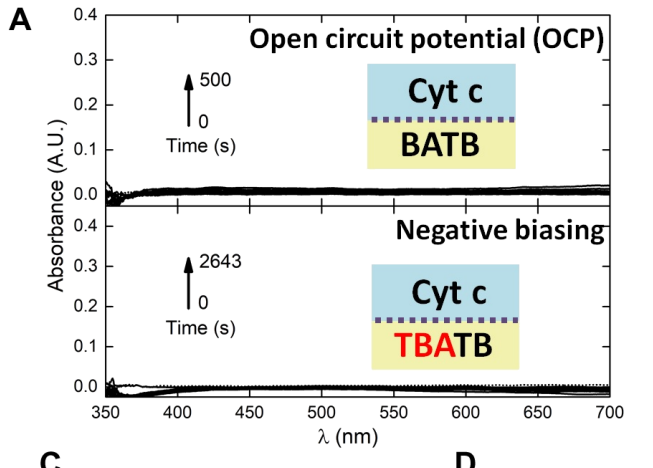

C
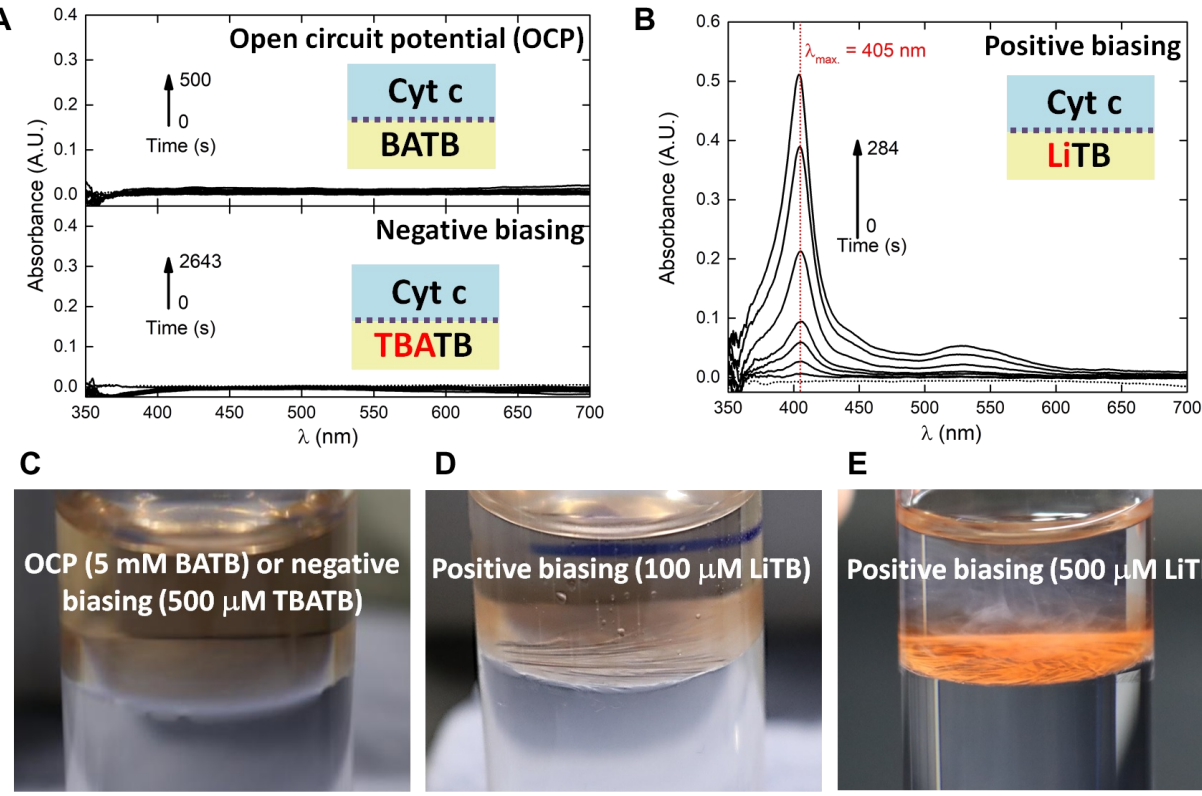

E
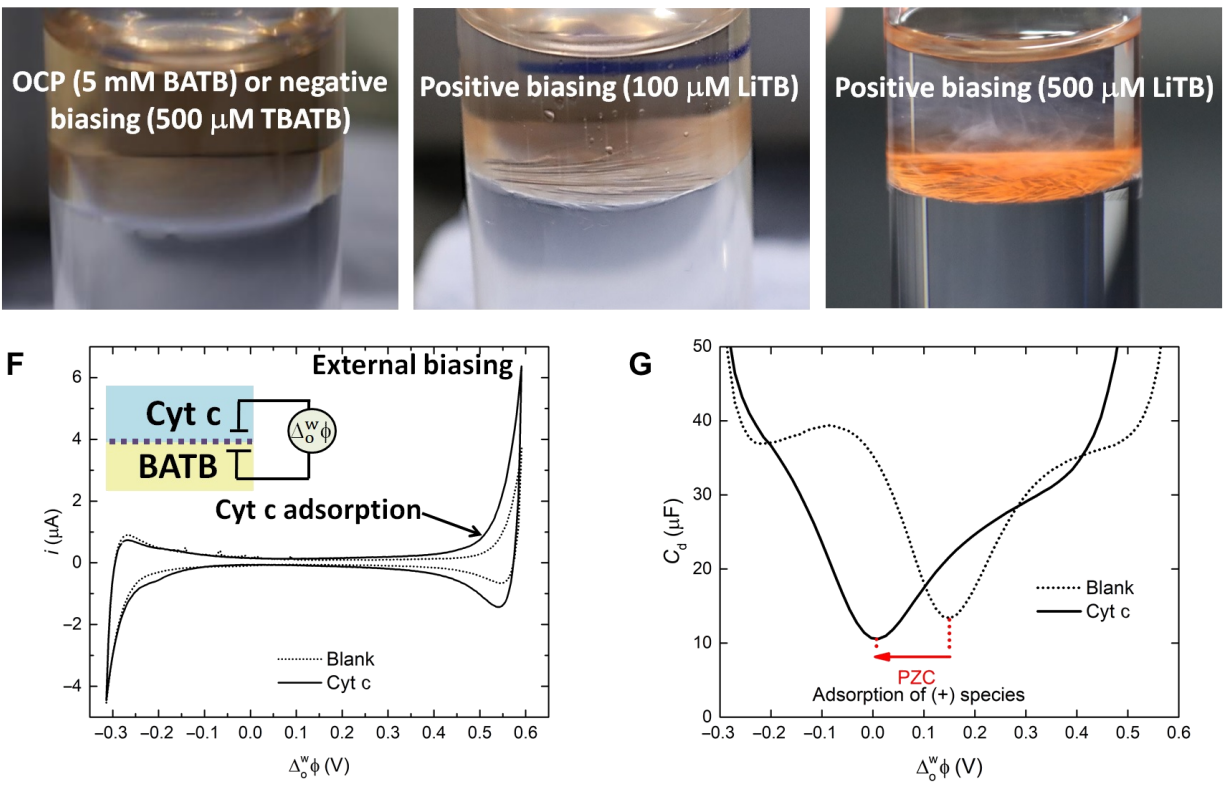

Fig. 2. Interfacial adsorption of Cyt $\mathrm{c}$ at the water-TFT interface monitored by UV/vis-TIR spectroscopy and voltammetric methods. (A) UV/vis-TIR spectra at OCP conditions (top) and under negative bias set by partition of tetrabutylammonium cations (TBA ${ }^{+}$; bottom). (B) UV/vis-TIR spectra under positive bias set by partition of $\mathrm{Li}^{+}$. A.U., arbitrary units. (C) Image of a bare water-TFT interface at OCP or under negative bias using $500 \mu$ M TBATB after 1 hour. (D and E) Images of the interfacial films of Cyt c formed under positive bias using 100 and $500 \mu \mathrm{M} \mathrm{LiTB}$, respectively, after 1 hour. Photo credit: Alonso Gamero-Quijano (University of Limerick, Ireland). (F) Repetitive cyclic voltammetry (30th cycle shown) over the full polarization potential window in the absence (dotted line) and presence (solid line) of Cyt c. (G) Differential capacitance curves, obtained after 30 cyclic voltammetry cycles, in the absence (dotted line) and presence (solid line) of Cyt c. Adsorption studies involving external biasing in (F) and (G) were performed using electrochemical cell 1 (see Fig. 5). PZC, potential of zero charge. 
bias is attributed to electrostatic and hydrophobic interactions between Cyt $\mathrm{c}$ and $\mathrm{TB}^{-}$at the interface (25-27). In line with the UV/ vis-TIR spectra, a thin film of adsorbed Cyt $\mathrm{c}$ was clearly visible at positive bias, whereas none was seen at OCP or with negative bias (Fig. 2, C and D). Excess positive bias (created by a fivefold increase in $\mathrm{Li}^{+}$partitioning) caused rapid aggregation of Cyt $\mathrm{c}$ into a thick film at the interface (Fig. 2E). The Cyt c films formed at the waterTFT interface were studied by confocal Raman microscopy. The upshifts of the core size markers bands $v_{4}, v_{2}$, and $v_{10}$ (see section S1) were attributed to the presence of $\mathrm{TB}^{-}$near the interface due to positive polarization (28). The Raman frequency upshifts ca. $4 \mathrm{~cm}^{-1}$, reflecting structural changes of the heme crevice (29), which support our findings by UV/vis-TIR spectroscopy.

Cyt $c$ adsorption at the interface was monitored and characterized using repetitive cyclic voltammetry (CV) scans over the full polarization potential window (Fig. 2F). After $30 \mathrm{CV}$ cycles, an increase in magnitude of the current at positive potentials is attributed to adsorption of a thin film of Cyt c. Differential capacitance measurements after $30 \mathrm{CV}$ cycles showed a negative shift in the capacitance minimum, known as the potential of zero charge (Fig. $2 \mathrm{G}$ ), indicating changes in the ionic distribution with an increase in net positive charge within the $\sim 1$-nm-thick inner layer of the back-toback electrochemical double layers (30-33). Thus, net positively charged Cyt $\mathrm{c}$ at $\mathrm{pH} 7$ adopts a preferred conformational orientation at the interface with positive residues, likely lysine, penetrating the inner layer.

\section{Molecular modeling of bias-induced Cyt $\mathrm{c}$ adsorption at the water-TFT interface}

To gain more insight into the anchoring and restructuring of Cyt c at the water-TFT interface, we performed MD simulations using interface models with the experimental ion distributions estimated from differential capacitance measurements at positive and negative biases at room temperature and neutral $\mathrm{pH}$ (for details, see section S2). At negative bias, no preferred orientation of Cyt $\mathrm{c}$ at the interface was observed during $0.1 \mu$ s of dynamics (see movie S1), with only short-lived, nonspecific interactions between the heme active site and the interface (Fig. 3A, left). However, at positive bias, organic $\mathrm{TB}^{-}$anions stabilize positively charged Lys residues and immobilize Cyt c (movie S2 and Fig. 3A, right) in a preferred ordered orientation that arises spontaneously in the simulations with the heme active site remaining normal to, and within $5 \AA$ of, the organic phase. The computed properties of this bias-induced pre-organization of the liquid biointerface for IET reactions are summarized in Fig. 3 (B to E), with further analysis provided in the section S3 (figs. S5 to $\mathrm{S} 15)$.

The computed density profiles of solvents and the ionic species across the interface (Fig. 3, B and C) show a dip in the water density curve close to the interface that corresponds to the position of the Cyt $c$ in the water phase. The computed density profiles are reproduced in repeats 1 and 2 (see section S3) at both biases (fig. S6). The most important features of the profiles, that is, the less pronounced dip in the water density and larger $\mathrm{TB}^{-}$population at the interface at positive bias, are also maintained for the extended $0.5-\mu$ s MD run (fig. S10D), confirming the propensity of Cyt c to migrate toward the organic phase. During positive biasing, the heme active site is kept anchored to the interface with a major population of bound states within $\sim 0.2 \mathrm{~nm}$ (fig. S5B), but at negative bias the heme does not make long-lived stable close contacts, usually sitting $\sim 1 \mathrm{~nm}$ away from the interface (fig. S5B). The interface-ordered orientation of the heme pocket at positive bias is further confirmed by the tight distribution of near-normal $90^{\circ}$ plane angles between the heme and the interface (Fig. 3D and fig. S5C), whereas a broader distribution roughly centered at $\sim 40^{\circ}$ is predicted at negative bias. The orientation at positive bias keeps the heme in close contact with the interface with only minor populations of short-lived more dissociated states due to room temperature protein dynamics in water (see Fig. 3E). The ordering effect of the $\mathrm{TB}^{-}$is evident from the tight pairing of $\mathrm{TB}^{-}$and Cyt c positively charged Lys sidechains via direct contacts (Fig. 3E and fig. S5E), which is facilitated by positive biasing induced increase in local concentration of $\mathrm{TB}^{-}$anions at the interface (Fig. 3, B and C), as also evident from the binding energy profiles (figs. S14 and S15).

To account for the potential impact of accumulation of $\mathrm{TB}^{-}$at the interface on the Cyt c orientation, we computed the minimum intermolecular distances (see fig. S5D) and counted the number of intermolecular contacts (Fig. 3E) between $\mathrm{TB}^{-}$and Lys residues in Cyt c. Only heavy atom (C, N, O, and S) direct contacts (within $0.45 \mathrm{~nm}$ ) were considered, and the number of contacts was normalized against the number of $\mathrm{TB}^{-}$ions ( 75 for positive bias and 6 for negative bias) in each system. At positive bias, persistent large populations of stable short-range distances are found. At negative bias, a far broader population is found including a large proportion of completely dissociated states with separations as large as $3 \mathrm{~nm}$ (fig. S5D). No perceptible contacts are found during the first half of simulation, after which short-lived contacts are occasionally sampled that appear to form and break randomly until the end of $0.1 \mu$ s of dynamics (Fig. 3E).

\section{Mimicking in vivo Cyt c peroxidase activity}

To mimic the oxidation of CL by Cyt c, a sacrificial organic electron donor, DcMFc (34), was introduced to the organic phase. The reduction of Cyt c-Fe(III) directly above the interface was confirmed (Fig. 4A) by the Soret band increase in intensity and red shift to $411 \mathrm{~nm}$, with increased intensity and resolution of the $\alpha$ - and $\beta$-bands (Fig. 4A, inset) (35). Interfacial reduction of Cyt c-Fe(III) is only possible if the active heme group is oriented toward the organic phase and the donor and acceptor come in close contact at positive bias.

Electrochemical measurements at electrified aqueous-organic interfaces sense all interfacial charge-transfer and charge-compensation (ion-pairing) events, whether due to IET, ion transfer (IT), or adsorption, respectively $(20,21)$. Repetitive CV cycling in the presence of aqueous Cyt $c$ and organic DcMFc identified two clear charge transfer events: a reversible diffusion-limited signal with a half-wave potential of $-0.215 \mathrm{~V}$ and an irreversible positive current wave with an onset potential of $+0.048 \mathrm{~V}$ (Fig. $4 \mathrm{~B}$ ). On the basis of its half-wave potential, the reversible signal was identified as the reversible IT of $\mathrm{DcMFc}^{+}$. The irreversible wave was attributed to an IET event.

Analyses using the peak current and potential for reversible and irreversible electrochemical electron transfer reactions $(36,37)$ revealed that the magnitude of both signals far exceeded that expected for the simple reduction of interfacial Cyt c-Fe(III) by DcMFc based on their bulk aqueous and organic concentrations; see section S4. The shape of the irreversible wave strongly indicates a catalytic reaction. Further, DcMFc is known to reduce dissolved $\mathrm{O}_{2}$ in the presence of a floating interfacial catalyst such as adsorbed porphyrins (38), and other diatomic molecules such as CO and $\mathrm{NO}(39,40)$ are known to bind at the heme site of the Cyt c-CL complex. Thus, we hypothesized that the partial denaturation of Cyt $\mathrm{c}$ by interfacial 


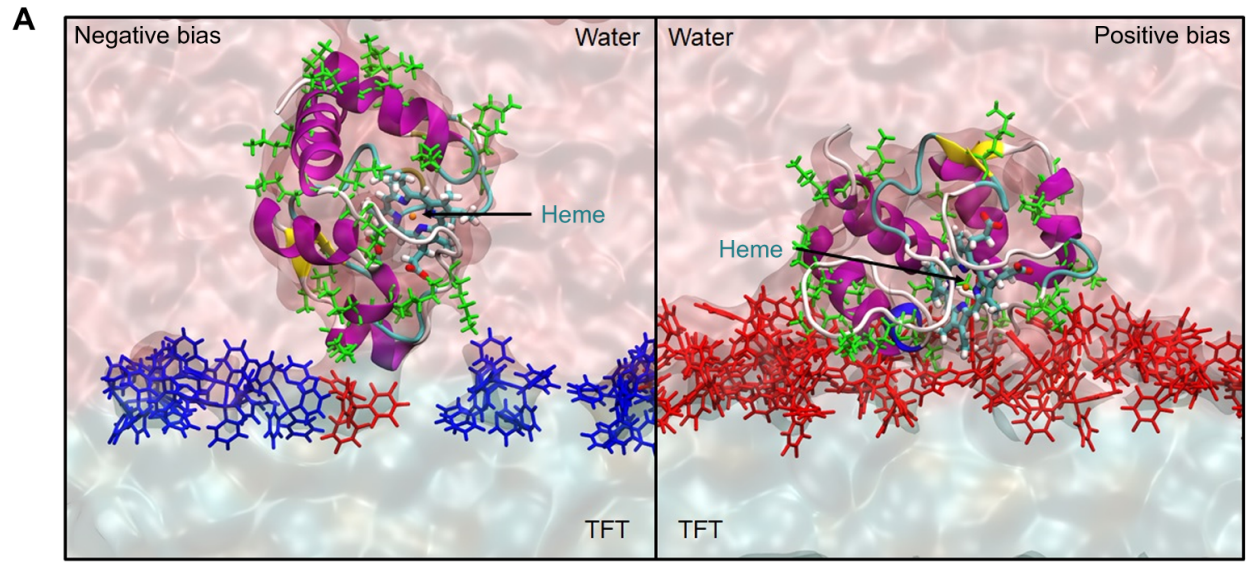

B

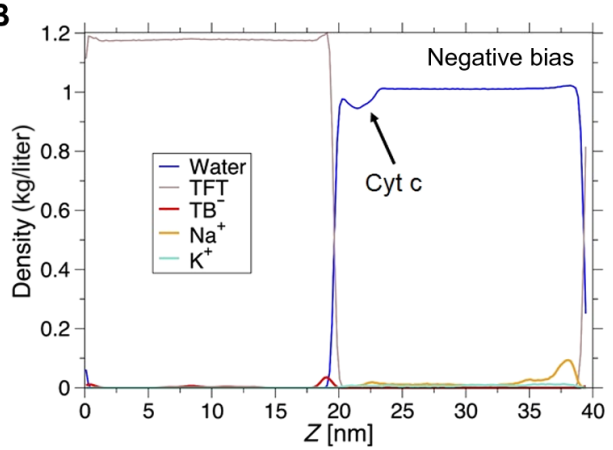

D

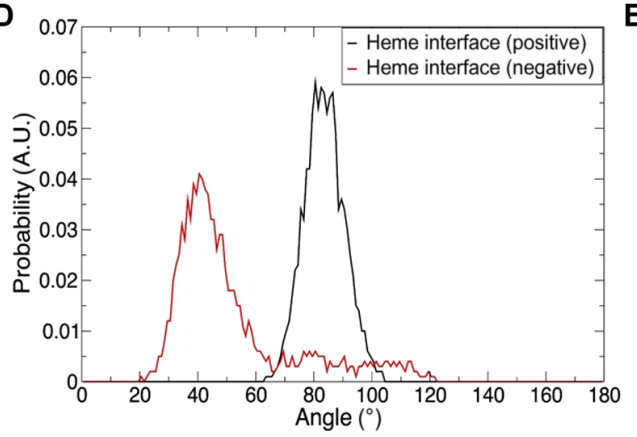

C

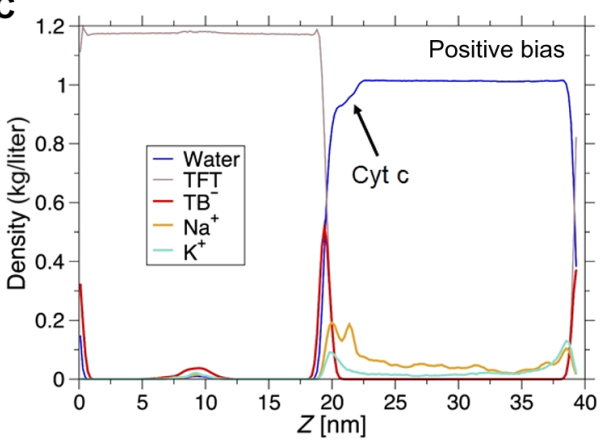

E

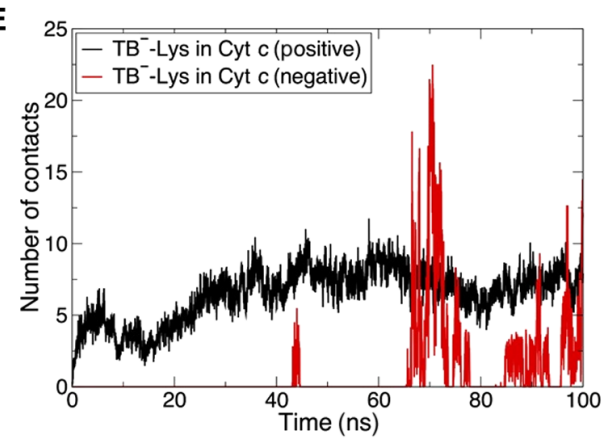

Fig. 3. Computed properties from MD of Cyt $\mathbf{c}$ at the water-TFT interface. (A) Representative snapshots showing the orientation of the Cyt $\mathrm{c}$ heme active site at negative bias (left) and positive bias (right). The Lys residues on the surface of Cyt $\mathrm{c}$ are shown as green ball and sticks, while the $\mathrm{BA}^{+}$and $\mathrm{TB}^{-}$ions from the organic phase are shown as blue and red ball and sticks, respectively. (B and C) Computed density profiles show the tighter docking of Cyt c at positive bias with (D) showing the tight distribution of near-normal orientations sampled between the heme plane and the interface at positive bias and (E) the Cyt $c$ Lys-TB ${ }^{-}$electrostatically bound pairs that create the ordered interface at positive bias.

adsorption and interaction with $\mathrm{TB}^{-}$triggered the enzymatic activity of Cyt c toward $\mathrm{O}_{2}$ reduction. This suggests that $\mathrm{O}_{2}$ accesses and binds to the heme site where it is reduced in a process mechanistically analogous to the peroxidase activity toward ROS $(8,41-43)$. Our hypothesis is also in line with findings by Casalini et al. (44) who immobilized on a gold electrode a Cyt $\mathrm{c}$ variant that featured an axial heme iron coordination position available for the binding of exogenous ligands. Under nondenaturing conditions, this Cyt c variant provided robust and persistent catalytic currents for $\mathrm{O}_{2}$ and $\mathrm{NO}_{2}{ }^{-}$reduction from $\mathrm{pH} 3$ to 11 (44).

To confirm the role of $\mathrm{O}_{2}$ in the IET catalytic wave, repetitive CV cycling in the presence of aqueous Cyt $\mathrm{c}$ and organic DcMFc was repeated under anaerobic conditions (Fig. 4C, red line, and section S5).
The 50-fold reduction of the IET current during the first CV cycle, from ca. 52 to $1.2 \mu \mathrm{A}$, as well as the stability of the electron transfer signal (fig. S18A), indicates that the IET event under anaerobic conditions is mechanistically distinct from that in the presence of $\mathrm{O}_{2}$. We attribute the modest IET under anaerobic conditions to the reduction of Cyt c-Fe(III) by DcMFc and subsequent protein-protein electron transfer between partially denatured Cyt $c$ in the inner layers and more native Cyt $\mathrm{c}$ in the outer layers (fig. S18B) (45). While multilayers on solid electrodes can only achieve this mechanism if the Cyt $\mathrm{c}$ molecules have sufficient conformational freedom to create these contacts (46), the required conformational freedom is naturally preprogrammed in our platform as the multilayers are floating on a dynamic soft interface. 
A

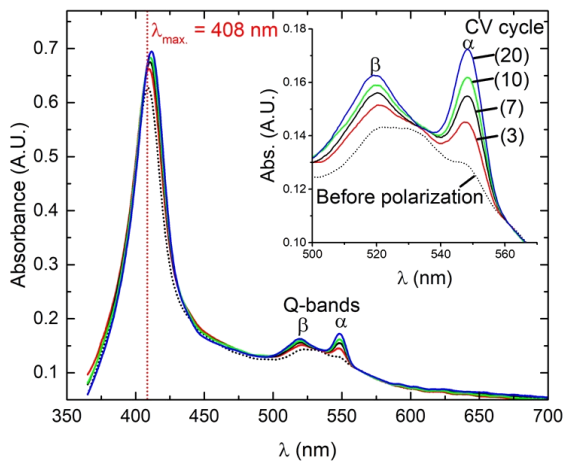

C

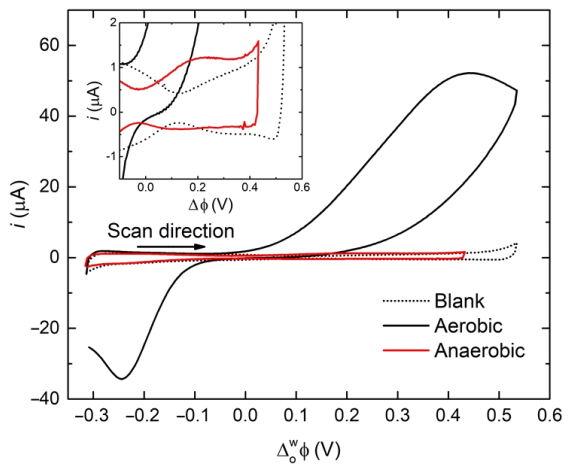

E

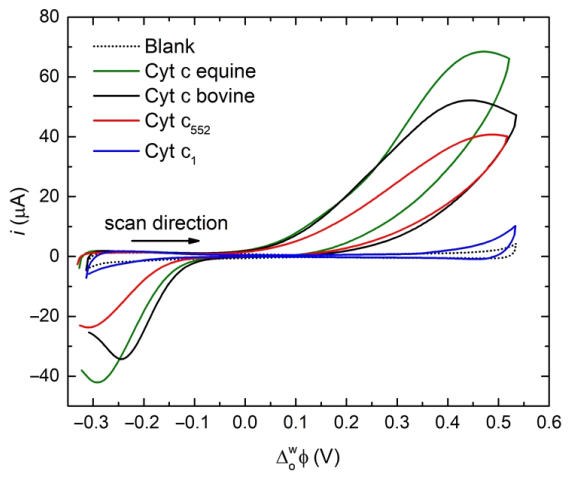

B

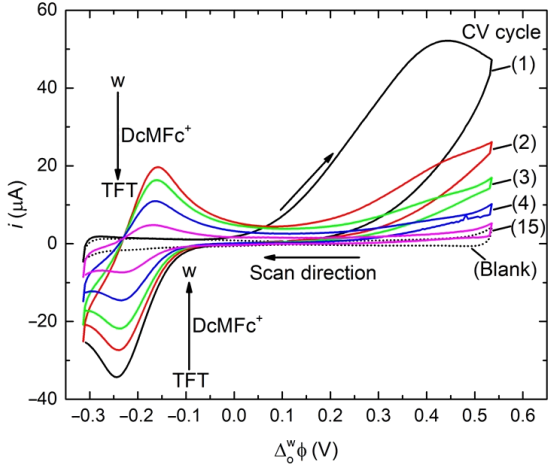

D

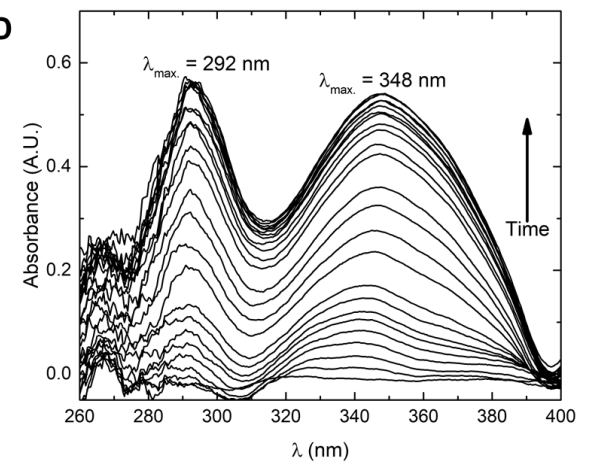

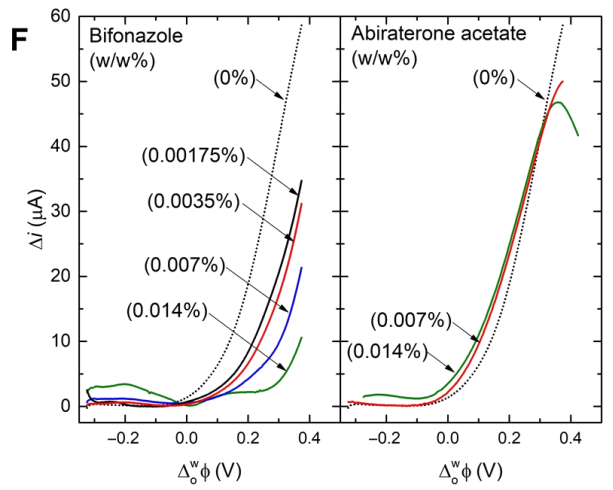

Fig. 4. IET studies of Cyt c at the water-TFT interface. (A) In situ parallel beam UV/vis absorbance spectra monitoring the reduction of Cyt c-Fe(III) on the aqueous side of the interface. Cyclic voltammetry in the presence of aqueous Cyt c and organic DcMFc under (B) aerobic conditions and (C) anaerobic conditions. (D) In situ parallel beam UV/vis absorbance spectra monitoring the formation of $\mathrm{H}_{2} \mathrm{O}_{2}$ on the aqueous side of the interface. (E) Cyclic voltammetry in the presence of $\mathrm{Cyt} \mathrm{c}$ proteins from different species and organic DcMFc. (F) Efficiency of bifonazole (left) and ineffectiveness of abiraterone acetate (right) to inhibit IET between Cyt c-Fe(III) and DcMFc. All IET studies were performed using electrochemical cell 2 , the iodometric titration study in (D) was performed using electrochemical cell 3 , and the inhibitory effect of the drugs bifonazole and abiraterone acetate on IET between Cyt c-Fe(III) and DcMFc in (F) was performed using electrochemical cell 4; see Fig. 5. The scan rate used in all electrochemical experiments was $20 \mathrm{mV} \cdot \mathrm{s}^{-1}$.

The IET catalytic wave decayed in magnitude exponentially with each CV cycle under aerobic conditions (Fig. 4B and fig. S18C). The latter was attributed to reduced accessibility of the heme as Cyt c oligomerizes at the interface, an unavoidable consequence of scanning to the positive edge of the polarizable potential window as demonstrated by our chemical polarization experiments vide supra and previously by Alvarez de Eulate et al. (19). A compact film of interfacial Cyt c oligomers created a barrier to IT of $\mathrm{DcMFc}^{+}$, with the magnitude of this reversible wave also decreasing exponentially with successive $\mathrm{CV}$ cycles under aerobic conditions (Fig. 4B and fig. S18D). The progressive accumulation of these oligomers was slower under anaerobic conditions, with no detectable blockage of the IT of $\mathrm{DcMFc}^{+}$after $1500 \mathrm{~s}$ (fig. S18D).
In situ parallel beam UV/vis absorbance spectroscopy was combined with double potential step chronoamperometry (DPSCA) to monitor the formation of $\mathrm{H}_{2} \mathrm{O}_{2}$ on the aqueous side of the interface through iodometric titration. The stepwise evolution of the triiodide bands at 292 and $348 \mathrm{~nm}$ was observed over 300 potential step cycles, with the magnitude of the absorbance indicating large production of $\mathrm{H}_{2} \mathrm{O}_{2}$ at the interface (Fig. 4D). In the absence of Cyt $\mathrm{c}$, no triiodide bands were recorded (see section S6).

The ability of our liquid biointerface to mimic in vivo Cyt c peroxidase activity was not restricted to Cyt $\mathrm{c}$ from bovine heart. Other peripheral membrane cytochrome proteins, including Cyt $c_{552}$ from Thermus thermophilus and Cyt $\mathrm{c}$ from equine heart, also behaved as potent $\mathrm{O}_{2}$ reduction electrocatalysts (Fig. $4 \mathrm{E}$, red and green lines, 
Cell 1: Interfacial Cyt c aggregation studies

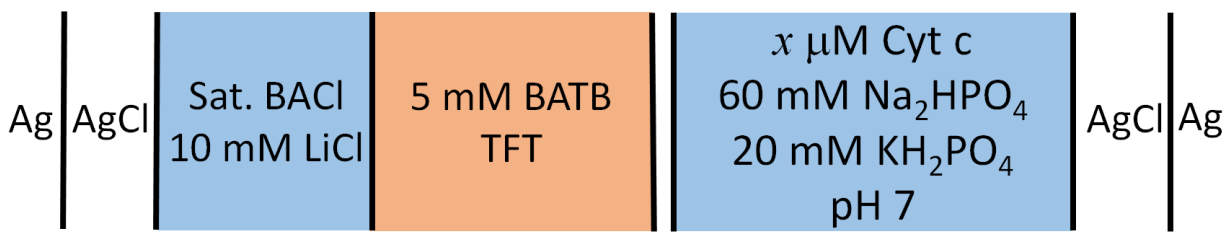

Cell 2: Interfacial electron transfer (IET) studies

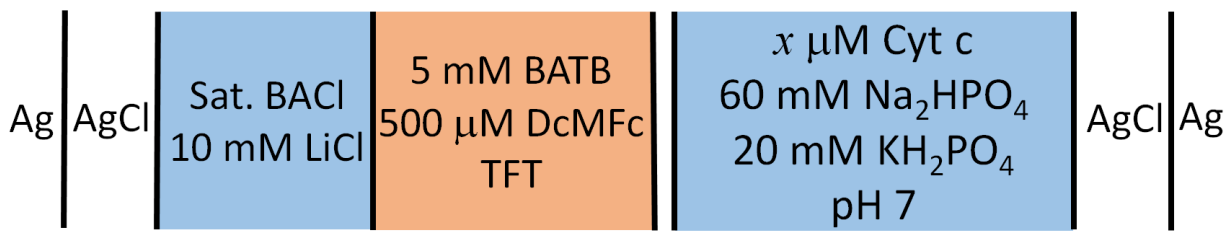

Cell 3: lodometric titration studies

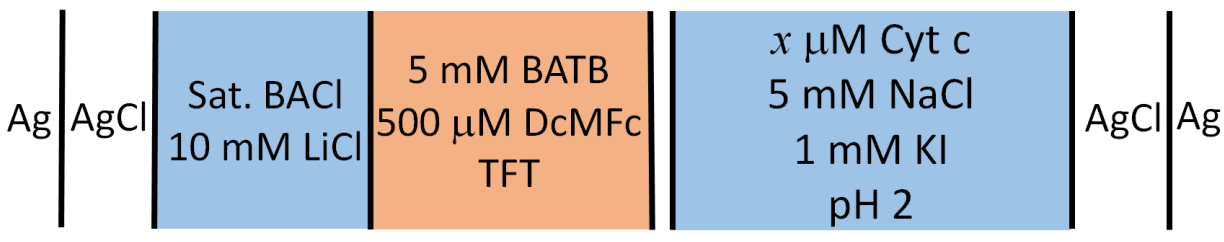

Cell 4: Inhibitory effect of drugs on IET between Cyt c-Fe(III) and DcMFc

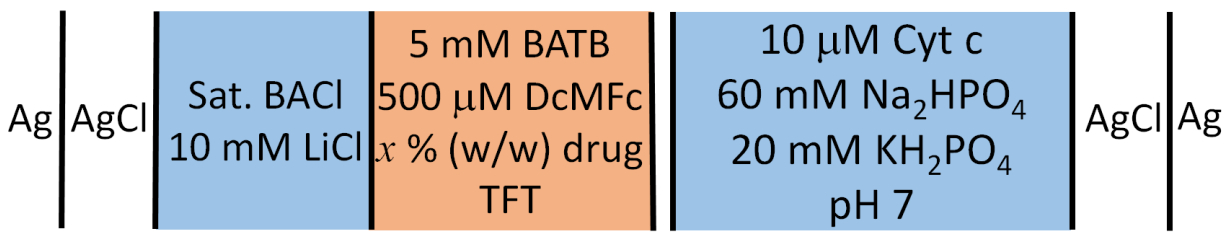

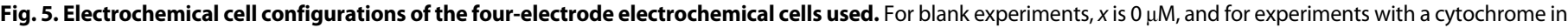

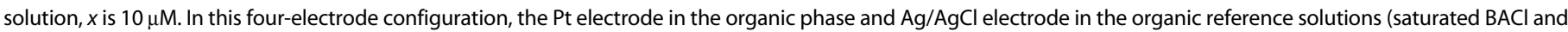

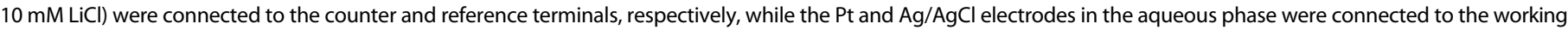

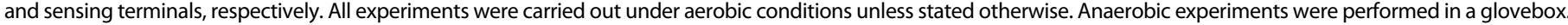

respectively). On the other hand, the transmembrane Cyt $c_{1}$ protein was redox inactive (Fig. 4E blue line), consistent with its role in vivo as an interprotein electron shuttle in the $b c 1$ complex catalytic mechanism $(47,48)$. Hence, Cyt $c_{1}$ does not show peroxidase activity during apoptosis, and its heme group is less accessible in the protein matrix compared to that of Cyt c (49). Cyt $c_{1}$ presented features consistent with a zwitterionic phospholipid penetrating an aqueousorganic interface (see section S7) (50). The hydrophobic helix of Cyt $c_{1}$ might be penetrating the water-TFT interface, with the protein behaving as a surfactant. Further studies with bovine serum albumin demonstrated that such a catalytic effect toward $\mathrm{O}_{2}$ reduction only occurs in the presence of some redox active c-type cytochrome proteins and is not a generic process catalyzed by the presence of a random protein adsorbed at the aqueous-organic interface (see section S8). These results demonstrate that our liquid biointerface distinguishes between the membrane activities of peripheral proteins, bound principally by ionic associations, and partially embedded transmembrane proteins.

In future, our electrified liquid biomembrane could provide a rapid electrochemical diagnostic platform to screen drugs designed in silico to target the heme crevice of Cyt c, bridging predictive modeling screens and rigorous in vitro or in vivo studies. For example, Bakan et al. (10) recently designed a pharmacophore model to identify repurposable drugs and novel compounds that inhibit the peroxidase activity of Cyt $\mathrm{c}$ in a dosage-dependent manner. One of the drugs identified by Bakan et al. (10) was bifonazole, an imidazolebased antifungal drug. Upon introducing bifonazole to our liquid biointerface in the presence of Cyt $c$ and DcMFc, the catalytic wave associated with $\mathrm{Cyt}$ c-catalyzed $\mathrm{O}_{2}$ reduction was completely suppressed (Fig. 4F, left). By contrast, the introduction of abiraterone acetate, an inhibitor of cytochrome P450 17 alpha-hydroxylase (CYP17) from a different family of cytochromes (51), did not have any effect on the IET (Fig. $4 \mathrm{~F}$, right). These results demonstrate the specificity of heme-targeting drugs to block Cyt c activity at our liquid biointerface.

\section{DISCUSSION}

Over the past three decades, electrochemistry at the interface between two immiscible electrolyte solutions (ITIES) has been heralded as a promising biomimetic technique providing the ideal platform to mimic the control of ion and electron transfer reactions across 
one leaflet of a cellular membrane. However, very little is known about electron transfer reactions with proteins at such electrified aqueous-organic interfaces, in hindsight primarily due to suboptimal conditions used in earlier studies with Cyt c $(52,53)$. In this article, we present electron transfer with the Cyt c family of redox-active proteins at an electrified aqueous-organic interface and successfully replicate a functional cell membrane biointerface, specifically the inner mitochondrial membrane at the onset of apoptosis. Our all-liquid approach provides an excellent model of the dynamic, fluidic environment of a cell membrane, with advantages over the current state-of-the-art bioelectrochemical methods reliant on rigid, solid-state architectures functionalized with biomimetic coatings [self-assembled monolayers (SAMs), conducting polymers, etc.].

Our experimental findings, supported by atomistic MD modeling, show that the adsorption, orientation, and restructuring of Cyt $\mathrm{c}$ to allow access to the redox center can all be precisely manipulated by varying the interfacial environment through external biasing of an aqueous-organic interface leading to direct IET reactions. Together, our MD models and experimental data reveal the ion-mediated interface effects that allow the dense layer of $\mathrm{TB}^{-}$ions to coordinate Cyt c surface-exposed Lys residues and create a stable orientation of Cyt $\mathrm{c}$ with the heme pocket oriented perpendicular to and facing toward the interface. This orientation, which arises spontaneously during the simulations at positive biasing, is conducive to efficient IET at the heme catalytic pocket. The ion-stabilized orthogonal orientation that predominates at positive bias is associated with more rapid loss of native contacts and opening of the Cyt c structure at positive bias (see fig. S8E). The perpendicular orientation of the heme pocket seems to be a generic prerequisite to induce electron transfer with Cyt $\mathrm{c}$ and also noted during previous studies on poly(3,4-ethylenedioxythiophene-coated (54) or SAM-coated (55) solid electrodes.

Evidence that Cyt c can act as an electrocatalyst to generate $\mathrm{H}_{2} \mathrm{O}_{2}$ and ROS species at an electrified aqueous-organic interface is groundbreaking due to its relevance in studying cell death mechanisms [apoptosis (56), ferroptosis (57), and necroptosis (58)] linked to ROS production. Thus, an immediate impact of our electrified liquid biointerface is its use as a rapid electrochemical diagnostic platform to screen drugs that down-regulate Cyt c (i.e., inhibit ROS production). These drugs are vital to protect against uncontrolled neuronal cell death in Alzheimer's and other neurodegenerative diseases. In proof-of-concept experiments, we successfully demonstrate the diagnostic capabilities of our liquid biointerface using bifonazole, a drug predicted to target the heme pocket (see Fig. 4F). Furthermore, our electrified liquid biointerface may play a role to detect different types of cancer (56), where ROS production is a known biomarker of disease.

\section{MATERIALS AND METHODS \\ Materials}

All chemicals were used as received without further purification. All aqueous solutions were prepared with ultrapure water (Millipore Milli-Q; specific resistivity, $18.2 \mathrm{megohm} \cdot \mathrm{cm})$. The organic solvent TFT (99+\%) was received from Acros Organics. DcMFc (97\%), bis(triphenylphosphoranylidene) ammonium chloride (BACl; 97\%), tetramethylammonium chloride ( $\geq 98 \%$ ), tetrabutylammonium chloride hydrate ( $\mathrm{TBACl} ; \geq 98 \%$ ), and lithium chloride ( $\mathrm{LiCl} ; \geq 95 \%$ ) were purchased from Sigma-Aldrich. Di-sodium hydrogen phosphate
$\left(\mathrm{Na}_{2} \mathrm{HPO}_{4}\right.$, anhydrous) and potassium dihydrogen phosphate $\left(\mathrm{KH}_{2} \mathrm{PO}_{4}\right.$, anhydrous) purchased from Sigma-Aldrich were used to prepare $\mathrm{pH} 7$ buffered solutions, i.e., the aqueous phase in our liquid biomembrane system. The final concentrations of phosphate salts were $60 \mathrm{mM} \mathrm{Na}_{2} \mathrm{HPO}_{4}$ and $20 \mathrm{mM} \mathrm{KH}_{2} \mathrm{PO}_{4}$ to achieve $\mathrm{pH}$ 7. Lithium tetrakis(pentafluorophenyl)borate diethyletherate (LiTB) was received from Boulder Scientific Company. The organic electrolyte salts of bis(triphenylphosphoranylidene)ammonium tetrakis(pentafluorophenyl)borate (BATB) and TBATB were prepared by metathesis of equimolar solutions of $\mathrm{BACl}$ (or TBACl) and $\mathrm{LiTB}$ in a methanolwater $(2: 1, \mathrm{v} / \mathrm{v})$ mixture. The resulting precipitates were filtered, washed, and recrystallized from acetone.

Cyt c-Fe(III) from bovine heart (Cyt c, $\geq 95 \%, 12.327 \mathrm{kDa}$ ) and Cyt c from equine heart (Cyt c, BioUltra, $\geq 99 \%, 12.384 \mathrm{kDa}$ ) were purchased from Sigma-Aldrich in their oxidized forms and used without further purification. T. thermophilus Cyt $\mathrm{c}_{552}$ (Cyt $\mathrm{c}_{552}$, $14.17 \mathrm{kDa}$ ) was isolated and purified as described previously by Soulimane et al. (59). The soluble Cyt $\mathrm{c}_{1}$ fragment (Cyt $\mathrm{c}_{1}$, ca. $26 \mathrm{kDa}$ ) was isolated and purified as described by Mooser et al. (60). Purity and homogeneity of the protein samples have been determined by SDS-polyacrylamide gel electrophoresis and gel filtration, respectively.

\section{Electrochemical experiments at the electrified aqueous-organic interface}

Electrochemical measurements at the aqueous-organic interface formed between an aqueous phosphate buffer solution and organic TFT solution, containing $5 \mathrm{mM}$ BATB organic electrolyte, were performed using a four-electrode electrochemical cell with an interfacial area of $1.53 \mathrm{~cm}^{2}$. A theoretical background to such experiments at an ITIES can be found in several articles and book chapters $(20,21,33,61)$. All the electrochemical measurements were carried out with a WaveDriver 20 bipotentiostat from Pine Research Instrumentation Inc. and controlled using AfterMath software version 1.4. The composition of the four-electrode electrochemical cells used is described in Fig. 5.

The applied potential $(E)$ in the four-electrode cell used to obtain cyclic voltammograms at the electrified water-TFT interface is defined as the potential difference established between the $\mathrm{Ag} / \mathrm{AgCl}$ reference electrode in the aqueous phase and that in the organic reference solution. The applied potential $(E)$ encompasses the interfacial Galvani potential difference $\left(\Delta_{\mathrm{o}}^{\mathrm{w}} \phi\right)$. The latter is defined as $\Delta_{\mathrm{o}}^{\mathrm{w}} \phi=\left(\phi^{\mathrm{w}}-\phi^{\mathrm{o}}\right)$, where $\phi^{\mathrm{w}}$ and $\phi^{\mathrm{o}}$ are the inner Galvani potentials of the aqueous and organic phases, respectively. In addition, the applied potential $(E)$ is determined by the nature of the reference electrodes used. These contributions to the applied potential $(E)$ are defined here as $\Delta E_{\text {ref. }}$ The calibration of the cyclic voltammograms obtained at the electrified water-TFT interface to the Galvani potential scale was performed following the relationship $E=\Delta_{\mathrm{o}}^{\mathrm{w}} \phi+\Delta E_{\mathrm{ref}}$. The critical value of $\Delta E_{\text {ref. }}$ was determined using the electrochemical half-wave IT response of $\mathrm{TMA}^{+}\left(E_{1 / 2}^{\mathrm{W} \rightarrow \mathrm{TMT}^{+}}\right)$and the standard IT potential of $\mathrm{TMA}^{+}$from the aqueous to TFT phase (known to be $\left.\Delta_{\mathrm{o}}^{\mathrm{w}} \phi_{\mathrm{tr} . \mathrm{TMA}}^{\ominus} \mathrm{TMT}^{+}=0.311 \mathrm{~V}\right)(62)$, as outlined in detail in our previous work (34).

\section{UV/Vis spectroscopy in total internal reflection}

In this experiment, the light source was directed toward the interface from underneath (through the organic phase) with the aid of focusing lenses, diaphragm, and mirrors; see schematic in Fig. 6. An angle of incidence (AOI) of ca. $75^{\circ}$ was used to ensure TIR conditions (see optical image in Fig. 6), as $\theta_{1}$ was calculated as $70.05^{\circ}$ using the 
Snell's law ( $\eta$ TFT $\sin \theta_{1}=\eta \mathrm{H}_{2} \mathrm{O} \sin \theta_{2}$; where $\eta \mathrm{TFT}=1.414$, $\eta \mathrm{H}_{2} \mathrm{O}=1.330$, and $\theta_{2}$ is assumed to be $90^{\circ}$ ).

The light source (Xe lamp HPX-2000, Ocean Optics) was guided by an optical fiber with a $200-\mu \mathrm{m}$ core (Newport) and focused on the water-TFT interface through plano-convex (Thorlabs) and achromatic lenses (Newport); see Fig. 6. All lenses were placed at their confocal lengths. The longer wavelengths $(\lambda>700 \mathrm{~nm})$ were cut by a Hot Mirror (Thorlabs) to avoid heating of the interfacial region. The reflected light was focused onto an optical fiber with a $1500 \mathrm{~mm}$ core (Thorlabs). The absorption spectra were recorded by a Maya 2000Pro (Ocean Optics).

\section{In situ parallel beam UV/Vis absorbance spectroscopy}

The spectrometer used was a USB 2000 Fiber Optic Spectrometer (Ocean Optics). The light source that was a DH-2000-BAL deuteriumhalogen (Ocean Optics) was guided through the optical fiber of $600 \mu \mathrm{m}$ in diameter (Ocean Optics, USA). The light beam was collimated using optical lenses (Thorlabs; focal length, $2 \mathrm{~cm}$ ) before and after the transmission of the beam through the electrochemical cell. The light beam passed through the electrochemical cell slightly above the water-TFT interface, i.e., through the aqueous phase. The interfacial Galvani potential difference $\left(\Delta_{\mathrm{o}}^{\mathrm{w}} \phi\right)$ was controlled using an Autolab PGSTAT204 potentiostat (Metrohm, Switzerland).

\section{Differential capacitance measurements}

AC voltammetry was performed in a four-electrode electrochemical cell. Differential capacitance was calculated from the interfacial admittance recorded using an Autolab FRA32M module in combination with the Autolab PGSTAT204 at a frequency of $5 \mathrm{~Hz}$ and root mean square amplitude of $5 \mathrm{mV}$. The scan direction was from negative toward more positive potentials, from ca. -0.3 to $+0.55 \mathrm{~V}$.

\section{Double potential step chronoamperometry}

DPSCA experiments were performed in a four-electrode electrochemical cell in conjunction with the in situ parallel beam UV/vis absorbance spectroscopy setup described vide supra. The first potential step was held at $\Delta_{\mathrm{o}}^{\mathrm{w}} \phi=+0.4 \mathrm{~V}$ for $10 \mathrm{~s}$. The second potential step was negative and held at $\Delta_{\mathrm{o}}^{\mathrm{w}} \phi=-0.3 \mathrm{~V}$ for $10 \mathrm{~s}$. This double potential step was repeated 300 times, and one UV/vis spectrum was recorded within each cycle.

\section{Confocal fluorescence microscopy}

Samples were imaged on an ImageXpress Micro Confocal High-Content Imaging System (Molecular Devices) with 20X S Plan Apo-objective.

\section{Confocal Raman spectroscopy}

Raman spectra were collected using a Renishaw Invia Qontor confocal Raman spectrometer (excitation $\lambda=532 \mathrm{~nm}$ ) in static mode (2400 grooves $/ \mathrm{mm}$ ). Because of vibrations of the liquid-liquid interface, and to maintain a good focus during the whole scan, the static mode was preferred to acquire Raman spectra over the synchroscan mode. Static mode allowed faster scan over the 650 to $1800 \mathrm{~cm}^{-1}$ region of interest. In average, 10 to $15 \mathrm{~s}$ was needed to record a full Raman spectrum.
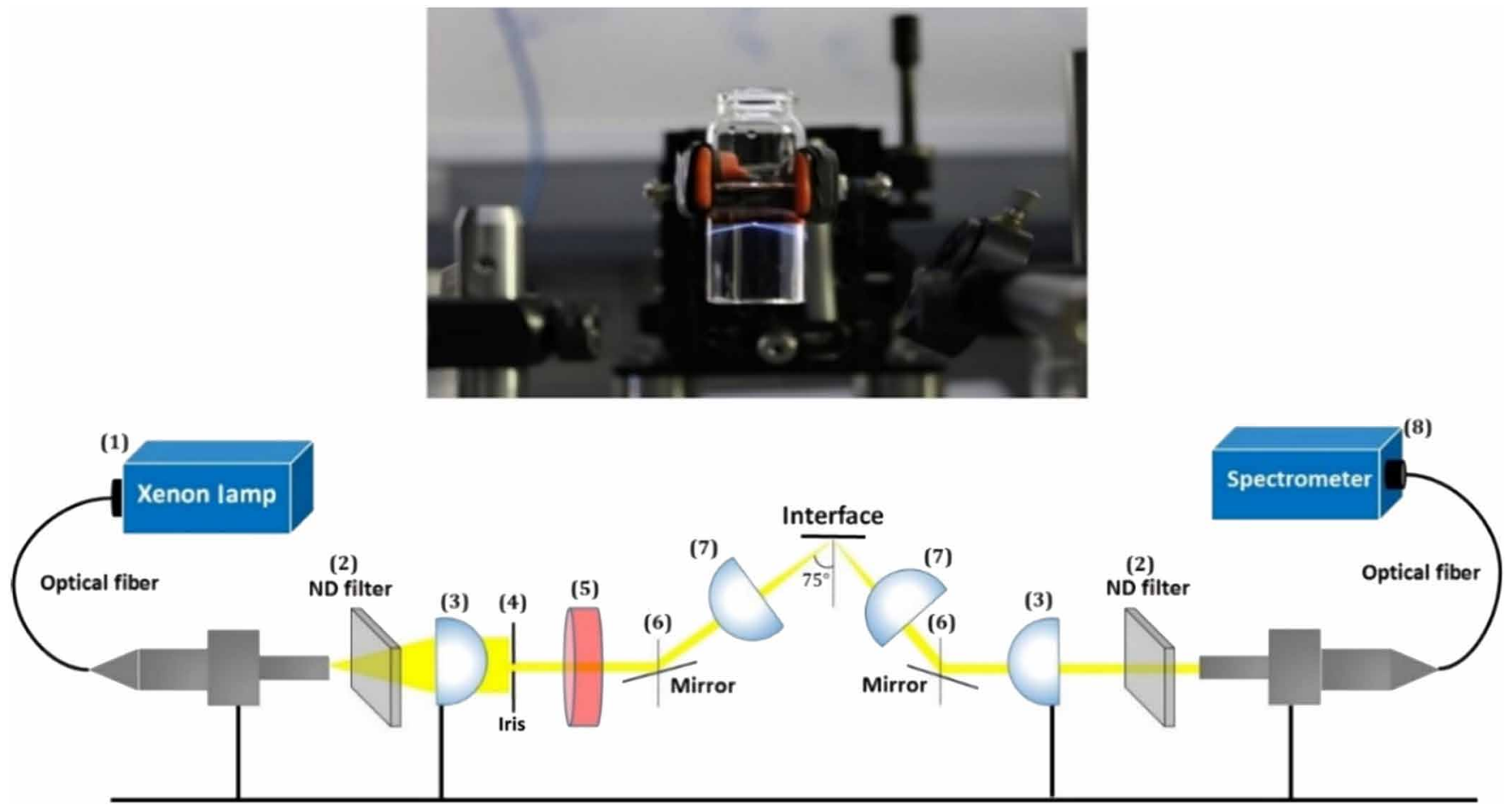

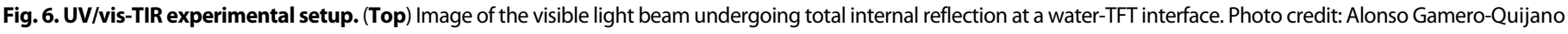

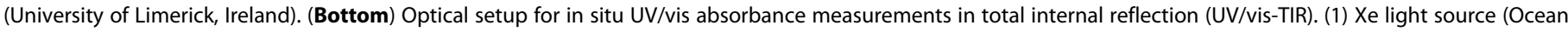

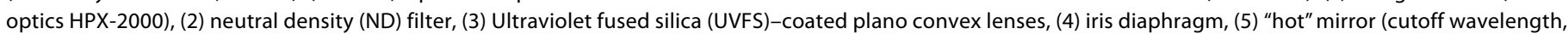
$800 \mathrm{~nm}$ ), (6) mirror, (7) achromatic doublet lenses, and (8) Ocean Optics Maya2000 Pro spectrometer. The angle of incidence (AOI) was set to $75^{\circ}$. 


\section{MD simulations}

All methods involving initial model setup for running MD simulations, details of simulation protocol including MD package, conditions, force field, and MD data processing, analyses, and visualization are given in section $\mathrm{S} 3$.

\section{SUPPLEMENTARY MATERIALS}

Supplementary material for this article is available at https://science.org/doi/10.1126/ sciadv.abg4119

View/request a protocol for this paper from Bio-protocol.

\section{REFERENCES AND NOTES}

1. D. Alvarez-Paggi, L. Hannibal, M. A. Castro, S. Oviedo-Rouco, V. Demicheli, V. Tórtora, F. Tomasina, R. Radi, D. H. Murgida, Multifunctional cytochrome c: Learning new tricks from an old dog. Chem. Rev. 117, 13382-13460 (2017).

2. I. Bertini, G. Cavallaro, A. Rosato, Cytochrome c: Occurrence and functions. Chem. Rev. 106, 90-115 (2006).

3. V. E. Kagan, H. A. Bayir, N. A. Belikova, O. Kapralov, Y. Y. Tyurina, V. A. Tyurin, J. Jiang, D. A. Stoyanovsky, P. Wipf, P. M. Kochanek, J. S. Greenberger, B. Pitt, A. A. Shvedova, G. Borisenko, Cytochrome $\mathrm{C} /$ cardiolipin relations in mitochondria: A kiss of death. Free Radic. Biol. Med. 46, 1439-1453 (2009).

4. R. Schweitzer-Stenner, Relating the multi-functionality of cytochrome $\mathrm{c}$ to membrane binding and structural conversion. Biophys. Rev. 10, 1151-1185 (2018).

5. J. Hanske, J. R. Toffey, A. M. Morenz, A. J. Bonilla, K. H. Schiavoni, E. V. Pletneva, Conformational properties of cardiolipin-bound cytochrome c. Proc. Natl. Acad. Sci. U.S.A. 109, 125-130 (2012).

6. G. Petrosillo, F. M. Ruggiero, G. Paradies, Role of reactive oxygen species and cardiolipin in the release of cytochrome c from mitochondria. FASEB J. 17, 2202-2208 (2003).

7. Y. Shidoji, K. Hayashi, S. Komura, N. Ohishi, K. Yagi, Loss of molecular interaction between cytochrome $\mathrm{c}$ and cardiolipin due to lipid peroxidation. Biochem. Biophys. Res. Commun. 264, 343-347 (1999).

8. V. E. Kagan, V. A. Tyurin, J. Jiang, Y. Y. Tyurina, V. B. Ritov, A. A. Amoscato, A. N. Osipov, N. A. Belikova, A. A. Kapralov, V. Kini, I. I. Vlasova, Q. Zhao, M. Zou, P. Di, D. A. Svistunenko, I. V. Kurnikov, G. G. Borisenko, Cytochrome $\mathrm{c}$ acts as a cardiolipin oxygenase required for release of proapoptotic factors. Nat. Chem. Biol. 1, 223-232 (2005).

9. A. Díaz-Quintana, G. Pérez-Mejías, A. Guerra-Castellano, M. A. De la Rosa, I. Díaz-Moreno, Wheel and deal in the mitochondrial inner membranes: The tale of cytochrome $c$ and cardiolipin. Oxid. Med. Cell. Longev. 2020, 6813405 (2020).

10. A. Bakan, A. A. Kapralov, H. Bayir, F. Hu, V. E. Kagan, I. Bahar, Inhibition of peroxidase activity of cytochrome c: De novo compound discovery and validation. Mol. Pharmacol. 88, 421-427 (2015)

11. R. Lagoa, A. K. Samhan-Arias, C. Gutierrez-Merino, Correlation between the potency of flavonoids for cytochrome $\mathrm{c}$ reduction and inhibition of cardiolipin-induced peroxidase activity. Biofactors 43, 451-468 (2017).

12. G. Silkstone, S. M. Kapetanaki, I. Husu, M. H. Vos, M. T. Wilson, Nitric oxide binding to the cardiolipin complex of ferric cytochrome c. Biochemistry 51, 6760-6766 (2012).

13. A. M. Firsov, E. A. Kotova, Y. N. Antonenko, Minocycline prevents peroxidative permeabilization of cardiolipin-containing bilayer lipid membranes mediated by cytochrome c. Biochem. Biophys. Res. Commun. 507, 510-513 (2018).

14. A. Patriarca, F. Polticelli, M. C. Piro, F. Sinibaldi, G. Mei, M. Bari, R. Santucci, L. Fiorucci, Conversion of cytochrome $c$ into a peroxidase: Inhibitory mechanisms and implication for neurodegenerative diseases. Arch. Biochem. Biophys. 522, 62-69 (2012).

15. J. Atkinson, A. A. Kapralov, N. Yanamala, Y. Y. Tyurina, A. A. Amoscato, L. Pearce, J. Peterson, Z. Huang, J. Jiang, A. K. Samhan-Arias, A. Maeda, W. Feng, K. Wasserloos, N. A. Belikova, V. A. Tyurin, H. Wang, J. Fletcher, Y. Wang, I. I. Vlasova, J. Klein-Seetharaman, D. A. Stoyanovsky, H. Bayîr, B. R. Pitt, M. W. Epperly, J. S. Greenberger, V. E. Kagan, A mitochondria-targeted inhibitor of cytochrome $c$ peroxidase mitigates radiationinduced death. Nat. Commun. 2, 497 (2011).

16. B. Hou, N. Laanait, H. Yu, W. Bu, J. Yoon, B. Lin, M. Meron, G. Luo, P. Vanysek, M. L. Schlossman, lon distributions at the water/1,2-dichloroethane interface: Potential of mean force approach to analyzing $X$-ray reflectivity and interfacial tension measurements. J. Phys. Chem. B 117, 5365-5378 (2013).

17. E. Leontidis, M. Christoforou, C. Georgiou, T. Delclos, The ion-lipid battle for hydration water and interfacial sites at soft-matter interfaces. Curr. Opin. Colloid Interface Sci. 19, 2-8 (2014).

18. L. Pérez-Fuentes, C. Drummond, J. Faraudo, D. Bastos-González, Anions make the difference: Insights from the interaction of big cations and anions with poly $(\mathrm{N}$ isopropylacrylamide) chains and microgels. Soft Matter 11, 5077-5086 (2015).

19. E. Alvarez de Eulate, S. O'Sullivan, D. W. M. Arrigan, Electrochemically induced formation of cytochrome c oligomers at soft interfaces. ChemElectroChem 4, 898-904 (2017).
20. P. Peljo, H. H. Girault, in Encyclopedia of Analytical Chemistry (John Wiley \& Sons, Ltd, Chichester, UK, 2012); http://doi.wiley.com/10.1002/9780470027318.a5306.pub2.

21. Z. Samec, Dynamic electrochemistry at the interface between two immiscible electrolytes. Electrochim. Acta 84, 21-28 (2012).

22. C. A. Chang, E. Wang, Z. Pang, Interfacial potential difference for the liquid/liquid ion partition process. J. Electroanal. Chem. 266, 143-155 (1989).

23. L. C. Petersen, R. P. Cox, The effect of complex-formation with polyanions on the redox properties of cytochrome c. Biochem. J. 192, 687-693 (1980).

24. K. C. U. Mugnol, R. A. Ando, R. Y. Nagayasu, A. Faljoni-Alario, S. Brochsztain, P. S. Santos, O. R. Nascimento, I. L. Nantes, Spectroscopic, structural, and functional characterization of the alternative low-spin state of horse heart cytochrome c. Biophys. J. 94, 4066-4077 (2008).

25. S. G. Booth, B. M. B. Felisilda, E. Alvarez De Eulate, O. J. R. Gustafsson, M. Arooj, R. L. Mancera, R. A. W. Dryfe, M. J. Hackett, D. W. M. Arrigan, Secondary structural changes in proteins as a result of electroadsorption at aqueous-organogel interfaces. Langmuir 35 5821-5829 (2019).

26. M. Arooj, D. W. M. Arrigan, R. L. Mancera, Characterization of protein-facilitated ion-transfer mechanism at a polarized aqueous/organic interface. J. Phys. Chem. B 123, 7436-7444 (2019).

27. D. W. M. Arrigan, M. J. Hackett, R. L. Mancera, Electrochemistry of proteins at the interface between two immiscible electrolyte solutions. Curr. Opin. Electrochem 12, 27-32 (2018)

28. T. K. Das, S. Mazumdar, S. Mitra, Characterization of a partially unfolded structure of cytochrome c induced by sodium dodecyl sulphate and the kinetics of its refolding. Eur. J. Biochem. 254, 662-670 (1998).

29. P. Hildebrandt, M. Stockburger, Cytochrome $\mathrm{c}$ at charged interfaces. 1. Conformational and redox equilibria at the electrode/electrolyte interface probed by surface-enhanced resonance Raman spectroscopy. Biochemistry 28, 6710-6721 (1989).

30. R. A. Hartvig, M. Van De Weert, J. Østergaard, L. Jorgensen, H. Jensen, Formation of dielectric layers and charge regulation in protein adsorption at biomimetic interfaces. Langmuir 28, 1804-1815 (2012).

31. D. Momotenko, C. M. Pereira, H. H. Girault, Differential capacitance of liquid/liquid interfaces of finite thicknesses: A finite element study. Phys. Chem. Chem. Phys. 14, 11268-11272 (2012).

32. C. Yufei, V. J. Cunnane, D. J. Schiffrin, L. Murtomäki, K. Kontturi, Interfacial capacitance and ionic association at electrified liquid/liquid interfaces. J. Chem. Soc. Faraday Trans. 87 107-114 (1991).

33. M. F. Suárez-Herrera, M. D. Scanlon, On the non-ideal behaviour of polarised liquid-liquid interfaces. Electrochim. Acta 328, 135110 (2019).

34. A. Gamero-Quijano, G. Herzog, M. D. Scanlon, Bioelectrochemistry of Cytochrome c in a closed bipolar electrochemical cell. Electrochem. Commun. 109, 106600 (2019).

35. A. Gamero-Quijano, F. Huerta, E. Morallón, F. Montilla, Modulation of the silica sol-gel composition for the promotion of direct electron transfer to encapsulated cytochrome $c$. Langmuir 30, 10531-10538 (2014).

36. R. Seeber, C. Zanardi, G. Inzelt, The inherent coupling of charge transfer and mass transport processes: The curious electrochemical reversibility. ChemTexts 2, 8 (2016).

37. A. J. Bard, L. R. Faulkner, Electrochemical Methods Fundamentals and Applications (John Wiley \& Sons, Inc., ed. 2, 2001).

38. P. Peljo, L. Murtomäki, T. Kallio, H. J. Xu, M. Meyer, C. P. Gros, J. M. Barbe, H. H. Girault, K. Laasonen, K. Kontturi, Biomimetic oxygen reduction by cofacial porphyrins at a liquid-liquid interface. J. Am. Chem. Soc. 134, 5974-5984 (2012).

39. G. Silkstone, S. M. Kapetanaki, I. Husu, M. H. Vos, M. T. Wilson, Nitric oxide binds to the proximal heme coordination site of the ferrocytochrome c/cardiolipin complex: Formation mechanism and dynamics. J. Biol. Chem. 285, 19785-19792 (2010).

40. S. M. Kapetanaki, G. Silkstone, I. Husu, U. Liebl, M. T. Wilson, M. H. Vos, Interaction of carbon monoxide with the apoptosis-inducing cytochrome c-cardiolipin complex. Biochemistry 48, 1613-1619 (2009)

41. Y. Y. Tyurina, V. Kini, V. A. Tyurin, I. I. Vlasova, J. Jiang, A. A. Kapralov, N. A. Belikova, J. C. Yalowich, I. V. Kurnikov, V. E. Kagan, Mechanisms of cardiolipin oxidation by cytochrome. Mol. Pharmacol. 70, 706-717 (2006).

42. N. A. Belikova, Y. A. Vladimirov, A. N. Osipov, A. A. Kapralov, V. A. Tyurin, M. V. Potapovich L. V. Basova, J. Peterson, I. V. Kurnikov, V. E. Kagan, Peroxidase activity and structural transitions of cytochrome $\mathrm{c}$ bound to cardiolipin-containing membranes. Biochemistry 45, 4998-5009 (2006)

43. L. V. Basova, I. V. Kurnikov, L. Wang, V. B. Ritov, N. A. Belikova, I. I. Vlasova, A. A. Pacheco, D. E. Winnica, J. Peterson, H. Bayir, D. H. Waldeck, V. E. Kagan, Cardiolipin switch in mitochondria: Shutting off the reduction of cytochrome $\mathrm{c}$ and turning on the peroxidase activity. Biochemistry 46, 3423-3434 (2007).

44. S. Casalini, G. Battistuzzi, M. Borsari, A. Ranieri, M. Sola, Catalytic reduction of dioxygen and nitrite ion at a Met80Ala cytochrome c-functionalized electrode. J. Am. Chem. Soc. 130, 15099-15104 (2008) 
45. E. Alvarez de Eulate, L. Qiao, M. D. Scanlon, H. H. Girault, D. W. M. Arrigan, Fingerprinting the tertiary structure of electroadsorbed lysozyme at soft interfaces by electrostatic spray ionization mass spectrometry. Chem. Commun. 50, 11829-11832 (2014).

46. M. K. Beissenhirtz, F. W. Scheller, W. F. M. Stöcklein, D. G. Kurth, H. Möhwald, F. Lisdat, Electroactive cytochrome c multilayers within a polyelectrolyte assembly. Angew. Chemie - Int. Ed. 43, 4357-4360 (2004).

47. Z. Zhang, L. Huang, V. M. Shulmeister, Y. I. Chi, K. K. Kim, L. W. Hung, A. R. Crofts, E. A. Berry, S. H. Kim, Electron transfer by domain movement in cytochrome bc1. Nature 392, 677-684 (1998).

48. O. Kokhan, C. A. Wraight, E. Tajkhorshid, The binding interface of cytochrome c and cytochrome $\mathrm{c} 1$ in the bc1 complex: Rationalizing the role of key residues. Biophys. J. 99, 2647-2656 (2010).

49. L. S. Kaminsky, Y. L. Chiang, T. E. King, Some properties of mammalian cardiac cytochrome c1. J. Biol. Chem. 250, 7280-7287 (1975).

50. H. A. Santos, V. García-Morales, C. M. Pereira, Electrochemical properties of phospholipid monolayers at liquid-liquid interfaces. ChemPhysChem 11, 28-41 (2010).

51. A. H. M. Reid, G. Attard, D. C. Danila, N. B. Oommen, D. Olmos, P. C. Fong, L. R. Molife, J. Hunt, C. Messiou, C. Parker, D. Dearnaley, J. F. Swennenhuis, L. W. M. M. Terstappen, G. Lee, T. Kheoh, A. Molina, C. J. Ryan, E. Small, H. I. Scher, J. S. De Bono, Significant and sustained antitumor activity in post-docetaxel, castration-resistant prostate cancer with the CYP17 inhibitor abiraterone acetate. J. Clin. Oncol. 28, 1489-1495 (2010).

52. Y. Imai, T. Sugihara, T. Osakai, Electron transfer mechanism of cytochrome $\mathrm{c}$ at the oil/ water interface as a biomembrane model. J. Phys. Chem. B 116, 585-592 (2012).

53. G. C. Lillie, S. M. Holmes, R. A. W. Dryfe, Electrochemistry of cytochrome $c$ at the liquidliquid interface. J. Phys. Chem. B 106, 12101-12103 (2002).

54. S. López-Bernabeu, F. Huerta, E. Morallón, F. Montilla, Direct electron transfer to cytochrome $c$ induced by a conducting polymer. J. Phys. Chem. C 121, 15870-15879 (2017).

55. K. Ataka, J. Heberle, Functional vibrational spectroscopy of a cytochrome c monolayer: SEIDAS probes the interaction with different surface-modified electrodes. J. Am. Chem. Soc. 126, 9445-9457 (2004).

56. B. Perillo, M. Di Donato, A. Pezone, E. Di Zazzo, P. Giovannelli, G. Galasso, G. Castoria, A. Migliaccio, ROS in cancer therapy: The bright side of the moon. Exp. Mol. Med. 52, 192-203 (2020).

57. X. Jiang, B. R. Stockwell, M. Conrad, Ferroptosis: Mechanisms, biology and role in disease. Nat. Rev. Mol. Cell Biol. 22, 266-282 (2021).

58. S. K. Hsu, W. T. Chang, I. L. Lin, Y. F. Chen, N. B. Padalwar, K. C. Cheng, Y. N. Teng, C. H. Wang, C. C. Chiu, The role of necroptosis in ros-mediated cancer therapies and its promising applications. Cancers 12, 1-23 (2020).

59. T. Soulimane, M. Von Walter, P. Hof, M. E. Than, R. Huber, G. Buse, Cytochrome-c552 from Thermus thermophilus: A functional and crystallographic investigation. Biochem. Biophys. Res. Commun. 237, 572-576 (1997).

60. D. Mooser, O. Maneg, C. Corvey, T. Steiner, F. Malatesta, M. Karas, T. Soulimane, B. Ludwig, A four-subunit cytochrome $\mathrm{bc}_{1}$ complex complements the respiratory chain of Thermus thermophilus. Biochim. Biophys. Acta 1708, 262-274 (2005).

61. Z. Samec, Electrochemistry at the interface between two immiscible electrolyte solutions (IUPAC Technical Report). Pure Appl. Chem. 76, 2147-2180 (2004).

62. A. J. Olaya, P. Ge, H. H. Girault, lon transfer across the water|trifluorotoluene interface. Electrochem. Commun. 19, 101-104 (2012).

63. L. Milazzo, L. Tognaccini, B. D. Howes, G. Smulevich, Probing the non-native states of Cytochrome c with resonance Raman spectroscopy: A tool for investigating the structure-function relationship. J. Raman Spectrosc. 49, 1041-1055 (2018).

64. A. Gamero-Quijano, M. Dossot, A. Walcarius, M. D. Scanlon, G. Herzog, Electrogeneration of a free-standing cytochrome c-Silica matrix at a soft electrified interface. Langmuir 37, 4033-4041 (2021).

65. Z. Samec, V. Mareček, D. Homolka, The double layer at the interface between two immiscible electrolyte solutions. J. Electroanal. Chem. Interfacial Electrochem. 126, 121-129 (1981).

66. N. Mirkin, J. Jaconcic, V. Stojanoff, A. Moreno, High resolution X-ray crystallographic structure of bovine heart cytochrome $\mathrm{c}$ and its application to the design of an electron transfer biosensor. Proteins 70, 83-92 (2008).

67. G. Madhavi Sastry, M. Adzhigirey, T. Day, R. Annabhimoju, W. Sherman, Protein and ligand preparation: Parameters, protocols, and influence on virtual screening enrichments. J. Comput. Aided Mol. Des. 27, 221-234 (2013).

68. S. Release, Schrödinger Maestro (2019).

69. J. Huang, S. Rauscher, G. Nawrocki, T. Ran, M. Feig, B. L. De Groot, H. Grubmüller, A. D. MacKerell, CHARMM36m: An improved force field for folded and intrinsically disordered proteins. Nat. Methods 14, 71-73 (2017).

70. A. D. MacKerell, D. Bashford, M. Bellott, R. L. Dunbrack, J. D. Evanseck, M. J. Field, S. Fischer, J. Gao, H. Guo, S. Ha, D. Joseph-McCarthy, L. Kuchnir, K. Kuczera, F. T. K. Lau, C. Mattos, S. Michnick, T. Ngo, D. T. Nguyen, B. Prodhom, W. E. Reiher, B. Roux, M. Schlenkrich, J. C. Smith, R. Stote, J. Straub, M. Watanabe, J. Wiórkiewicz-Kuczera, D. Yin,
M. Karplus, All-atom empirical potential for molecular modeling and dynamics studies of proteins. J. Phys. Chem. B 102, 3586-3616 (1998)

71. K. Kaszuba, P. A. Postila, O. Cramariuc, M. Sarewicz, A. Osyczka, I. Vattulainen, T. Róg, Parameterization of the prosthetic redox centers of the bacterial cytochrome $b c_{1}$ complex for atomistic molecular dynamics simulations. Theor. Chem. Acc. 132, 1370 (2013).

72. B. Hess, H. Bekker, H. J. C. Berendsen, J. G. E. M. Fraaije, LINCS: A linear constraint solver for molecular simulations. J. Comput. Chem. 18, 1463-1472 (1997).

73. S. Miyamoto, P. A. Kollman, Settle: An analytical version of the SHAKE and RATTLE algorithm for rigid water models. J. Comput. Chem. 13, 952-962 (1992).

74. R. W. Hockney, The potential calculation and some applications. Methods Comput. Phys. 9 , 135-211 (1970).

75. T. Darden, D. York, L. Pedersen, Particle mesh Ewald: An $N \cdot \log (N)$ method for Ewald sums in large systems. J. Chem. Phys. 98, 10089-10092 (1993).

76. H. J. C. Berendsen, J. P. M. Postma, W. F. Van Gunsteren, A. Dinola, J. R. Haak, Molecular dynamics with coupling to an external bath. J. Chem. Phys. 81, 3684-3690 (1984).

77. W. Humphrey, A. Dalke, K. Schulten, VMD: Visual Molecular Dynamics. J. Mol. Graph. 14, 33-38 (1996).

78. R. B. Best, G. Hummer, W. A. Eaton, Native contacts determine protein folding mechanisms in atomistic simulations. Proc. Natl. Acad. Sci. U.S.A. 110, 17874-17879 (2013).

79. R. T. McGibbon, K. A. Beauchamp, M. P. Harrigan, C. Klein, J. M. Swails, C. X. Hernández, C. R. Schwantes, L. P. Wang, T. J. Lane, V. S. Pande, MDTraj: A modern open library for the analysis of molecular dynamics trajectories. Biophys. J. 109, 1528-1532 (2015)

80. P. A. Kollman, I. Massova, C. Reyes, B. Kuhn, S. Huo, L. Chong, M. Lee, T. Lee, Y. Duan, W. Wang, O. Donini, P. Cieplak, J. Srinivasan, D. A. Case, T. E. Cheatham, Calculating structures and free energies of complex molecules: Combining molecular mechanics and continuum models. Acc. Chem. Res. 33, 889-897 (2000).

81. R. Kumari, R. Kumar; Open Source Drug Discovery Consortium, A. Lynn, g_mmpbsa-A GROMACS tool for high-throughput MM-PBSA calculations. J. Chem. Inf. Model. 54, 1951-1962 (2014).

82. E. K. J. Tuominen, C. J. A. Wallace, P. K. J. Kinnunen, Phospholipid-cytochrome C interaction: Evidence for the extended lipid anchorage. J. Biol. Chem. 277, 8822-8826 (2002).

83. H. Pelletier, J. Kraut, Crystal structure of a complex between electron transfer partners, cytochrome c peroxidase and cytochrome c. Science 258, 1748-1755 (1992).

84. C. Kawai, F. M. Prado, G. L. C. Nunes, P. Di Mascio, A. M. Carmona-Ribeiro, I. L. Nantes, $\mathrm{pH}$-dependent interaction of cytochrome $\mathrm{c}$ with mitochondrial mimetic membranes. J. Biol. Chem. 280, 34709-34717 (2005).

85. C. Kawai, F. S. Pessoto, T. Rodrigues, K. C. U. Mugnol, V. Tórtora, L. Castro, V. A. Milícchio I. L. S. Tersariol, P. Di Mascio, R. Radi, A. M. Carmona-Ribeiro, I. L. Nantes, pH-sensitive binding of cytochrome $\mathrm{c}$ to the inner mitochondrial membrane. Implications for the participation of the protein in cell respiration and apoptosis. Biochemistry $\mathbf{4 8 ,}$ 8335-8342 (2009).

86. X. Daura, K. Gademann, B. Jaun, D. Seebach, W. F. Van Gunsteren, A. E. Mark, Peptide folding: When simulation meets experiment. Angew. Chem. Int. Ed. 38, 236-240 (1999).

87. K. J. McKenzie, F. Marken, Accumulation and reactivity of the redox protein Cytochrome $C$ in mesoporous films of $\mathrm{TiO}_{2}$ phytate. Langmuir 19, 4327-4331 (2003).

88. S. C. Feifel, K. R. Stieger, A. Kapp, D. Weber, M. Allegrozzi, M. Piccioli, P. Turano, F. Lisdat, Insights into interprotein electron transfer of human cytochrome $c$ variants arranged in multilayer architectures by means of an artificial silica nanoparticle matrix. ACS Omega 1, 1058-1066 (2016).

89. F. A. Armstrong, H. A. O. Hill, N. J. Walton, Direct electrochemistry of redox proteins. Acc. Chem. Res. 21, 407-413 (1988).

90. M. Rüdiger, in Semiconductor Electrochemistry (John Wiley \& Sons, 2015), pp. 127-168.

91. W. Schmickler, Electron-transfer reactions across liquid|liquid interfaces. J. Electroanal. Chem. 428, 123-127 (1997).

92. R. A. Marcus, Theory of electron-transfer rates across liquid-liquid interfaces. J. Phys. Chem. 94, 4152-4155 (1990).

93. R. A. Marcus, Theory of electron-transfer rates across liquid-liquid interfaces. 2. Relationships and application. J. Phys. Chem. 95, 2010-2013 (1991).

Acknowledgments: D.T. thanks Science Foundation Ireland (SFI) for computing resources at the SFI/Higher Education Authority Irish Center for High-End Computing (ICHEC). Funding: M.D.S. and A.F.M.-O. acknowledge Science Foundation Ireland (SFI) under grant no. 13/SIRG/2137 and the European Research Council through a Starting Grant (agreement no. 716792). A.G.-Q. acknowledges funding received from an Irish Research Council (IRC) Government of Ireland Postdoctoral Fellowship Award (grant number GOIPD/2018/252). G.H. and M.D. are grateful to the French Programme Investissement d'Avenir (PIA) “Lorraine 
Université d'Excellence" (reference no. ANR-15-IDEX-04-LUE). M.D.S. and G.H. are grateful to the support of the IRC and Campus France for travel support between the French and Irish groups through their joint ULYSSES program. D.T. thanks Science Foundation Ireland (SFI) for support (awards grant numbers 15/CDA/3491 and 12/RC/2275_P2). Author contributions: A.G.-Q. co-wrote the manuscript, carried out the majority of the spectro-electrochemical experiments, and assisted with the design of the MD simulations. S.B. and P.-A.C. carried out MD simulations and co-wrote the manuscript. A.F.M.-O. carried out preliminary spectroelectrochemical measurements with Cyt c and codeveloped the UV/vis-TIR setup. C.B. carried out the experiments with bifonazole. A.D. isolated and purified $\mathrm{Cyt}_{\mathrm{C}} \mathrm{C}_{52}$ and $\mathrm{Cyt}_{\mathrm{C}} \mathrm{C}_{1}$. T.S. supervised the isolation and purification of purified $C_{y t} C_{552}$ and $C_{y t} c_{1}$ and developed these experimental protocols. M.D. assisted with the spectro-electrochemical measurements and codeveloped the UV/vis-TIR setup. D.T. co-wrote the manuscript and supervised all MD simulations. G.H. and M.D.S. co-wrote the manuscript, devised the project, obtained the funding, and supervised all spectro-electrochemical experiments. Competing interests: The authors declare that they have no competing interests. Data and materials availability: All data needed to evaluate the conclusions in the paper are present in the paper and/or the Supplementary Materials. Input and output files of the MD simulation data of $\mathrm{Cyt} \mathrm{C}$ at $\mathrm{pH} 7$ at the water-TFT interface may be accessed online through the Zenodo data repository at https://zenodo.org/record/5044080\#.YN4jPehKg2w.

Submitted 4 January 2021

Accepted 17 September 2021

Published 5 November 2021

$10.1126 /$ sciadv.abg4119 


\section{ScienceAdvances}

\section{Modulating the pro-apoptotic activity of cytochrome $\mathrm{c}$ at a biomimetic electrified interface}

Alonso Gamero-QuijanoShayon BhattacharyaPierre-André CazadeAndrés F. Molina-OsorioCillian BeecherAhmed DjeghaderTewfik SoulimaneManuel DossotDamien ThompsonGrégoire HerzogMicheál D. Scanlon

Sci. Adv., 7 (45), eabg4119. • DOI: 10.1126/sciadv.abg4119

View the article online

https://www.science.org/doi/10.1126/sciadv.abg4119

Permissions

https://www.science.org/help/reprints-and-permissions 